DOI: $10.24193 /$ tras.65E.4

Published First Online: 02/25/2022

\section{TRANSFORMATIONAL, TRANSACTIONAL LEADERSHIP, AND PERCEPTIONS \\ OF ORGANIZATIONAL PERFORMANCE: \\ THE MODERATING ROLE OF RELATIONAL AUTHENTICITY AS A LEADER}

\section{Min-Hyu KIM}

\author{
Min-Hyu KIM \\ Assistant Professor, Department of Public Administration, \\ Dongguk University-Seoul, Seoul, Republic of Korea \\ E-mail: mkim2021@dongguk.edu \\ ORCID: 0000-0001-8078-0526
}

\section{Abstract}

This study examines whether relational authenticity as a leader, a relatively new concept in the nonprofit literature, moderates the relationship between transformational, transactional leadership, and perceptions of organizational performance. Using an online survey experiment of executive directors at 403 nonprofit organizations, this study tests the hypothesis of the positive-negative asymmetry effects, which states that negative impressions are more impactful than positive ones. The findings illustrate that, in the case of positive personal behavior, a transformational leader (vs. transactional leader) acting favorably has a statistically significant positive influence on organizational performance. However, in the case of negative personal behavior, the treatment had null findings. This study suggests that nonprofit leaders should pay attention to achieving relational authenticity as a leader to ensure the sustainability of transformational leadership effects.

Keywords: leadership, relational authenticity, organizational performance. 


\section{Introduction}

Nonprofits' board members and academic proponents of introducing transformational leadership into nonprofit service delivery have repeatedly claimed the importance of transformational leadership because of its significance in improving organizational performance (Jaskyte, 2004; Paarlberg and Lavigna, 2010). Transformational leadership is defined as a style of leadership that heightens one's consciousness of the collective interest of the organizational members and helps them achieve their collective goals (García-Morales et al., 2012). In contrast, transactional leadership focuses on promoting leaders and their followers' individual interests and achieving the satisfaction of contractual obligations on behalf of both leaders and followers by establishing objectives and monitoring the results (Bass and Avolio, 2000).

Scholars have questioned to what extent the transformational leadership techniques of public and private sectors can be applied to the nonprofit sector (Boerner and Gebert, 2012; Brimhall, 2019). Previous studies have also suggested that the differences among the nonprofit, public, and private sectors could play a role (Riggio et al., 2004). Moreover, several studies have suggested that nonprofit organizations' specific context may result in different consequences of transformational and transactional leadership (Rowold and Rohmann, 2009; Mayr, 2017; Boerner and Gebert, 2012); however, empirical evidence concerning this issue is limited. Methodologically, the previous literature on transformational leadership's effects on organizational performance in the nonprofit sector has depended heavily upon the case or observational studies in which supervisors' leadership style is likely to be endogenous for perceptions of organizational performance (Rowold and Rohmann, 2009; Brimhall, 2019).

Recently, theories on relational authenticity have also drawn attention. Generally, achieving relational authenticity requires that followers accord leaders the legitimacy to promote a set of values on behalf of a community (Harter, 2002, p. 382). Although several scholars (e.g., Shamir and Eilam, 2005) have discussed repeatedly the possible positive effects of relational authenticity on organizational performance, an empirical evaluation of whether this holds true in nonprofit organizations is missing.

A positive-negative asymmetry perspective can be applied to explain relational authenticity's potential to achieve a more active and effective leadership. The positive-negative asymmetry effect theory assumes that negative and positive events are not equally salient, although probably of equal magnitude or emotional valence (Baumeister et al., 2001; Peeters and Czapinski, 1990). Stated simply, negative behavior affects the outcomes of both transformational and transactional leaderships, although positive behavior influences only transformational leadership's effects. This present study extends and tests the theory of positive-negative asymmetry using a randomized experiment to investigate whether or not leaders' negative personal behavior has detrimental effects on perceptions of organizational performance.

The remainder of the paper is organized as follows. Section 2 reviews the literature and develops the hypotheses. Section 3 describes the methodology, and Section 4 presents the results. Finally, Section 5 concludes the paper. 


\section{Literature review}

\subsection{Transformational, transactional leadership, and organizational performance in nonprofit organizations}

The distinctive characteristics of nonprofit organizations present special challenges for nonprofit leadership. Given that nonprofit wages are so low and that many nonprofit employees seek assistance (Kim and Charbonneau, 2020), nonprofit leaders must motivate their followers to work hard despite low wages. Fortunately, nonprofits can overcome the challenge of limited payroll by devising alternative ways to appeal to employees. This is because the salary is not always the most important factor motivating an employee to accept a job offer, or to remain with a nonprofit organization, which is why transformational leaders must communicate nonprofit organizations' value and vision to their followers (Creative Business Resources, 2016). Executive directors who want to take nonprofit organizations to a higher level may consider the transformational leadership approach to inspire, create a better work environment, call employees and volunteers to take action, and keep donors to stay connected (University of Notre Dame, 2019).

Several recent critical reviews of the transformational and transactional leadership construct include the work of Van Knippenberg and Sitkin (2013), who suggested that management scholarship should more clearly define the distinct aspects of leadership through empirical studies to overcome the following three problems in the previous literature. First, a clear, conceptual definition of transformational and transactional leadership is lacking. Second, theories do not sufficiently explain the causal model explaining how the outcome is contingent on moderating influences. Lastly, the most frequently used measurement tools are invalid because they do not capture the dimensional structure specified by Bass and Avolio's (1994) full-range theory. As a result, a mismatch between what the previous literature has shown and what a future workforce should know about transformational and transactional leadership remains.

Previous studies have suggested the need to examine the effect of leadership style on organizational performance within the nonprofit context (e.g., Van Slyke and Johnson, 2006; Geer, Maher and Cole, 2008), whereas transformational leadership has been associated with a number of positive outcomes across samples and cultures in the public and for-profit sectors (Wang et al., 2011; Whittington, Goodwin and Murray, 2004; Bellé, 2014). For example, Rowold and Rohmann (2009) used data from German nonprofit orchestras and found that transformational leaders contribute to organizational performance by motivating and inspiring their followers. Rowold et al. (2014) also found that transformational leaders increased organizational performance by painting an optimistic future that provided both meaning and challenges for followers in fire departments and Protestant church offices in Germany.

Although these studies provide insightful contributions to the literature and help us understand transformational leadership's effect on organizational performance, empirical evidence in nonprofit organizations remains limited. Given that boards in the nonprofit sector look for executive directors who demonstrate transformational leadership, studying 
whether transformational leadership subsequently leads to better organizational performance is proper and timely. Therefore, this study hypothesizes the following:

Hypothesis 1: Nonprofit executives are more likely to evaluate organizational performance positively when the organization's leader is a transformational leader (vs. transactional leader).

\subsection{The moderating role of relational authenticity as a leader}

In this study, relational authenticity as a leader is considered a facilitator of organizational performance, rather than a direct determining force. Eagly (2005) defined relational authenticity as 'advocating goals that are grounded in shared values, and authentic leaders' actions promote goals that benefit the large communities' (p. 460). Given that authentic leaders contribute to the community other than fulfilling their organizational mission because followers accord legitimacy to relational authenticity in leadership, leaders' inappropriate behavior can undermine an organization's performance (Avolio et al., 2004). Hence, transformational leaders can be perceived as inauthentic when their behavior outside the workplace is inappropriate. The moderation argument of authentic leadership suggests that the positive relationship between transformational leadership and organizational performance can be strengthened in nonprofits when the community perceives that leaders' personal behavior is positive. Specifically, compared to the performance of organizations with inauthentic leaders, the performance of nonprofits with more authentic leaders tends to be better, as their followers accept and support them because of their relational authenticity (e.g., Chen et al., 2018).

Cumulatively, these findings help explain relational authenticity as a moderating factor in the relationship between transformational leadership and organizational performance. Transformational leadership can be a direct determining force, but its effect can be conditioned by leaders' relational authenticity, such as exemplary behavior they show, public values that they believe in, or their personal leadership styles. Based on the moderation argument on relational authenticity and perceptions of organizational performance described in the previous literature (Kotzé and Nel, 2017; George et al., 2007), there is good reason to propose that relational authenticity moderates the relationship between transformational, transactional leadership, and perceptions of organizational performance, particularly in the nonprofit context.

\subsection{The positive-negative asymmetry effect}

In social psychology, the positive-negative asymmetry effects have been repeatedly identified (Peeters and Czapinski, 1990; Skowronski and Carlston, 1989). For instance, Peeters and Czapinski (1990) defined the positive-negative asymmetry effects as biases according to which respondents tend to respond more strongly to negative stimuli than to positive ones. A positive-negative asymmetry effect is a phenomenon in which negative information about a new acquaintance has a greater impact on impressions than positive information (Baumeister et al., 2001). For example, when nonprofit leaders evaluate man- 
agers in other organizations, the negative information about him/her may have a greater impact than positive stimuli.

Considering the frequent, daily exchange among leaders, staff and citizens due to nonprofit organizations' huge contributions to local communities (De Vita and Fleming, 2001), the influence of relational authenticity as a leader can be especially significant for nonprofits (Third Sector Company, 2020). Therefore, if transformational or transactional leaders commit a misdemeanor even outside the workplace, these behaviors can adversely affect the performance of nonprofit organizations. Conversely, the effect of favorable personal conduct will be weaker than that of adverse behaviors due to positive-negative asymmetry effects. This is because a negative expectation concerning moral behavior may be weighted more heavily in a perceiver's mind than a positive one and may lead to an asymmetry favoring the confirmation of negative expectations over positive ones (Martijn et al., 1992; Reeder and Brewer, 1979; Reeder and Coovert, 1986; Skowronski and Carlston, 1987; Skowronski and Carlston, 1992). The present study assumed that the difference between transformational leadership $\times$ positive behaviors and transactional leadership $\times$ positive behaviors is statistically significant, whereas the two confidence intervals (transformational leadership $\times$ negative behaviors and transactional leadership $\times$ negative behaviors) are overlapped due to positive-negative asymmetry effects. Thus, a testable implication of the positive-negative asymmetry hypothesis is whether the positive relationship between transformational leadership and organizational performance is strengthened in nonprofits with leaders who demonstrate positive behaviors. This expectation led us to the following hypotheses:

Hypothesis 2: Leaders' negative behaviors weaken both transformational and transactional leadership effects, whereas leaders' positive behavior increases transformational leadership effect only.

Hypothesis 2-1: In the case of positive personal behavior, a transformational leader acting favorably has a positive influence on organizational performance compared to transactional leadership effects.

Hypothesis 2-2: In the case of negative personal behavior, leadership styles have no significant effect on organizational performance.

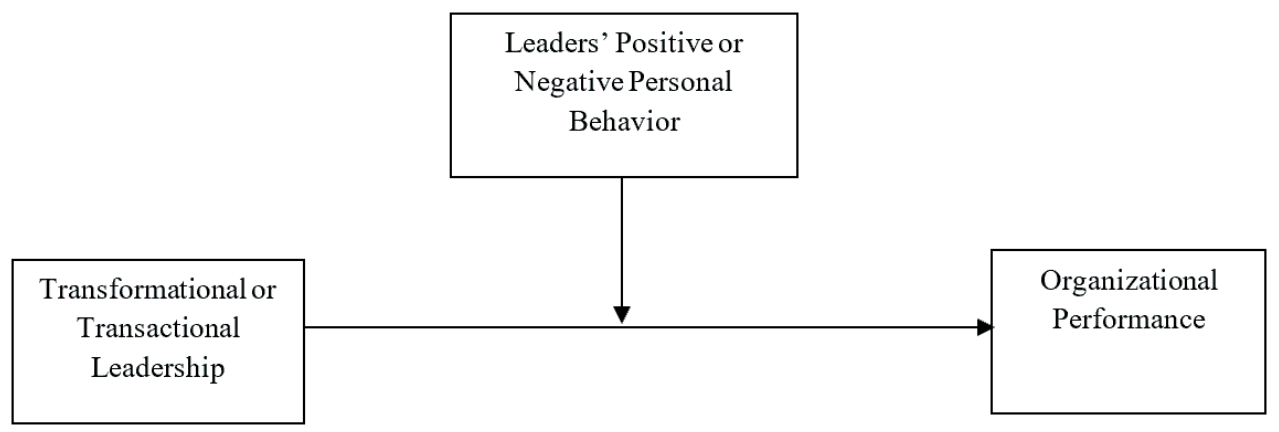

Figure 1: Positive-negative asymmetry effect framework 


\section{Research design}

\subsection{Sample and data}

To test the positive-negative asymmetry hypothesis, this study designed a between-subjects survey experiment based on a hypothetical transformational/transactional leadership scenario that was embedded in an online survey. Given that transformational and transactional leaderships are not mutually exclusive, determining which one impacts organizational performance is difficult. Further, some unmeasured difference or common cause could affect the results, or causal relationships may be reversed (e.g., organizational performance could influence different types of leaders). Although experimental designs have been used extensively to study a more active and effective leadership in the business administration literature (Dvir et al., 2002; Barling et al., 1996; Jung and Avolio, 2000), such experiments have not been conducted in the nonprofit leadership scholarship to the same degree as its other aspects. Thus, this study uses a randomized survey experiment to overcome the methodological limitations of previous studies.

This study used multiple modes of communication to yield higher response rates (Dillman et al., 2014). The sample size was determined based on an a priori power calculation using G*Power software (Faul et al., 2007). The appropriate sample size was calculated to find an effect that is small in size (.2) at $80 \%$ power given $\alpha=0.05$. For the data collection, of the 1,018 organizations that had received the survey, 403 nonprofit organizations participated (132 emails bounced back), representing 50 states and an overall response rate of $39.6 \%{ }^{1}$

In addition, the two waves were administered online. The initial invitation was sent in October 2019, and the first and second reminders were sent in November 2019, with an interval of two weeks each. The initial invitation was internet-based, but postal invitations, including a link to the online questionnaire, were sent out to executive leaders with non-disclosed email addresses on the websites. The first and second reminders were emailed to the leaders who shared their email accounts. Appendix A presents the experimental vignette.

1 This study performed several manipulation checks to exclude those who may have ignored the stimuli or failed to receive their assigned treatment. Eight participants were deleted from the sample based on the results of the checks. Moreover, based on the exclusion criteria used in previous literature (e.g., Mason and Suri, 2012; Oppenheimer, Myvis and Davidenko, 2009), participants who took an unusually long or short time were also excluded from the analyses. Six participants from the sample who completed the survey too quickly (i.e., less than 120 seconds) or too slowly (i.e., more than 15 minutes) were dropped from the sample. Before the manipulation checks, the participants took an average of 7.2 minutes (range $=0.20-467.85, S D=23.04$ ) to complete the survey. After the checks, the average time to complete the survey was 6.1 minutes (range $=2.00-14.48, \mathrm{SD}=2.45$ ). This study also inspected the participants' Internet protocol (IP) addresses to ensure that none completed the survey twice (Horton, Rand and Zeckhauser, 2011). Further, participants responded to the item 'Are you responding honestly?' using the response options 'no', 'maybe', and 'yes' to check for their attention. Four participants failed this attention check and were excluded. A total of 403 participants remained in the sample, following the manipulation checks. 
The data were collected from an original survey of nonprofit leaders in 50 states in the United States. This sample consisted of 1,018 stratified random sampled nonprofit organizations from the National Center for Charitable Statistics (2013) database. ${ }^{2}$ With respect to organizational missions, respondents slightly differ in percentages (Table 1). Given the differences in the percentages between the sample and population in this study, nonprofit practitioners may need to consider this if seeking to adopt this study's implications to practice.

Table 1: A comparison between population and this study's sample $(\mathrm{N}=403)$

\begin{tabular}{lcc}
\hline \multicolumn{1}{c}{ Organizational Missions } & $\begin{array}{c}\text { National Center for } \\
\text { Charitable Statistics } \\
(2013)\end{array}$ & $\begin{array}{c}\text { National Survey of } \\
\text { Nonprofit Leaders }\end{array}$ \\
\hline A: Arts, Culture, and Humanities & $9.23 \%$ & $13.02 \%$ \\
\hline B: Educational Institutions and Related Activities & $15.74 \%$ & $24.26 \%$ \\
\hline C: Environmental Quality, Protection, and Beautification & $2.26 \%$ & $2.96 \%$ \\
\hline D: Animal Related & $2.00 \%$ & $2.37 \%$ \\
\hline E: Health - General and Rehabilitative & $8.77 \%$ & $7.10 \%$ \\
\hline F: Mental Health, Crisis Intervention & $2.85 \%$ & $3.55 \%$ \\
\hline G: Disease, Disorders, Medical Disciplines & $2.44 \%$ & $2.37 \%$ \\
\hline H: Medical Research & $0.69 \%$ & $0.59 \%$ \\
\hline I: Crime, Legal Related & $1.74 \%$ & $2.37 \%$ \\
\hline J: Employment, Job Related & $1.48 \%$ & $2.37 \%$ \\
\hline K: Food, Agriculture, and Nutrition & $1.15 \%$ & $2.37 \%$ \\
\hline L: Housing, Shelter & $7.01 \%$ & $3.55 \%$ \\
\hline M: Public Safety, Disaster Preparedness, and Relief & $1.98 \%$ & $1.18 \%$ \\
\hline N: Recreation, Sports, Leisure, Athletics & $5.91 \%$ & $2.37 \%$ \\
\hline O: Youth Development & $2.44 \%$ & $1.18 \%$ \\
\hline P: Human Services - Multipurpose and Other & $14.30 \%$ & $13.60 \%$ \\
\hline Q: International, Foreign Affairs, and National Security & $2.17 \%$ & $0.00 \%$ \\
\hline R: Civil Rights, Social Action, Advocacy & $0.66 \%$ & $2.37 \%$ \\
\hline S: Community Improvement, Capacity Building & $4.30 \%$ & $1.78 \%$ \\
\hline T: Philanthropy, Voluntarism, and Grantmaking Foundations & $4.47 \%$ & $2.37 \%$ \\
\hline U: Science and Technology Research Institutes, Services & $0.59 \%$ & $0.59 \%$ \\
\hline V: Social Service Research Institutes, Services & $0.28 \%$ & $0.00 \%$ \\
\hline W: Public. Society Benefit: Multipurpose and Other & $1.09 \%$ & $4.73 \%$ \\
\hline X: Religion Related, Spiritual Development & $6.08 \%$ & $1.18 \%$ \\
\hline Y: Mutual/Membership Benefit Organizations, Other & $0.27 \%$ & $0.00 \%$ \\
\hline Z: Unknown & $0.08 \%$ & $0.00 \%$ \\
\hline Number of Observation & 216,924 & 403 \\
\hline
\end{tabular}

Source: Author

2 Here, strata were made by randomly selecting $10 \%$ of the organizations from each organizational mission. A self-administered survey required obtaining the email addresses of the selected 501(c)(3) organizations' executive directors, accomplished by visiting each nonprofit's webpage. 
Using the randomizer function embedded in Qualtrics, an online survey software, participants were randomly assigned to five groups: (1) transformational leadership with negative personal behavior; (2) transformational leadership with positive behavior; (3) transactional leadership with negative behavior; (4) transactional leadership with positive behavior; and (5) control group. The first four groups are the treatment groups. Then, respondents answered questions on organizational performance. Table 2 presents the sample's demographic characteristics. An analysis of the differences between the control and treatment groups showed that groups were balanced at the outset - none of the differences found across the groups concerning the basic organizational characteristics were statistically significant at the 0.01 level (Table 2).

Figure 2 shows the study's experimental design. The questionnaire was finalized after being pretested with several nonprofit executive directors. Their feedback, which was instrumental in designing the project survey, suggested that the participants thought of themselves as commenting on the hypothetical material.

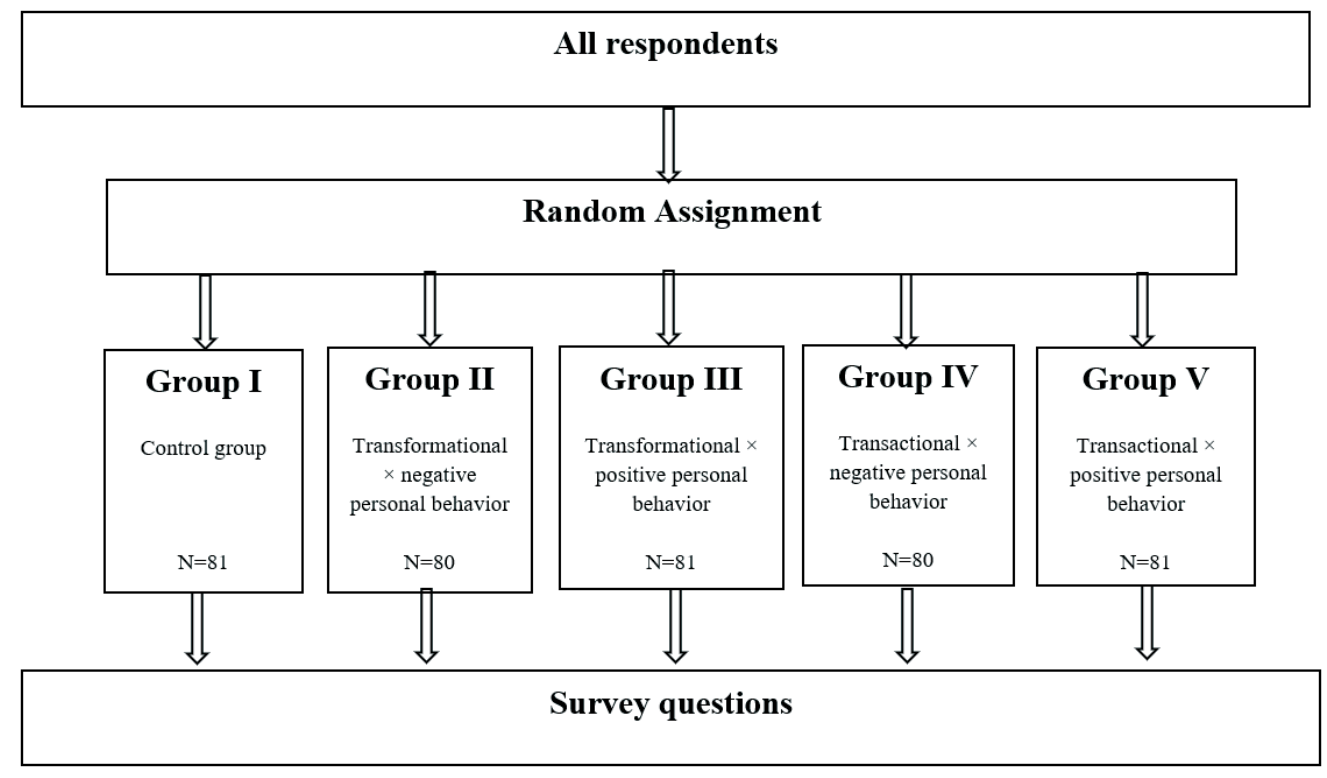

Figure 2: Experimental design

Source: Author

\subsection{Experimental design}

For the transformational and transactional leadership conditions, participants were exposed to a prompt that portrayed the leader as a transformational or transactional leader, respectively. For the negative behavior condition, participants were told about a nonprofit leader who received damaging media attention after a video was released showing him berating police officers at a traffic stop and posturing aggressively and condescendingly. In 


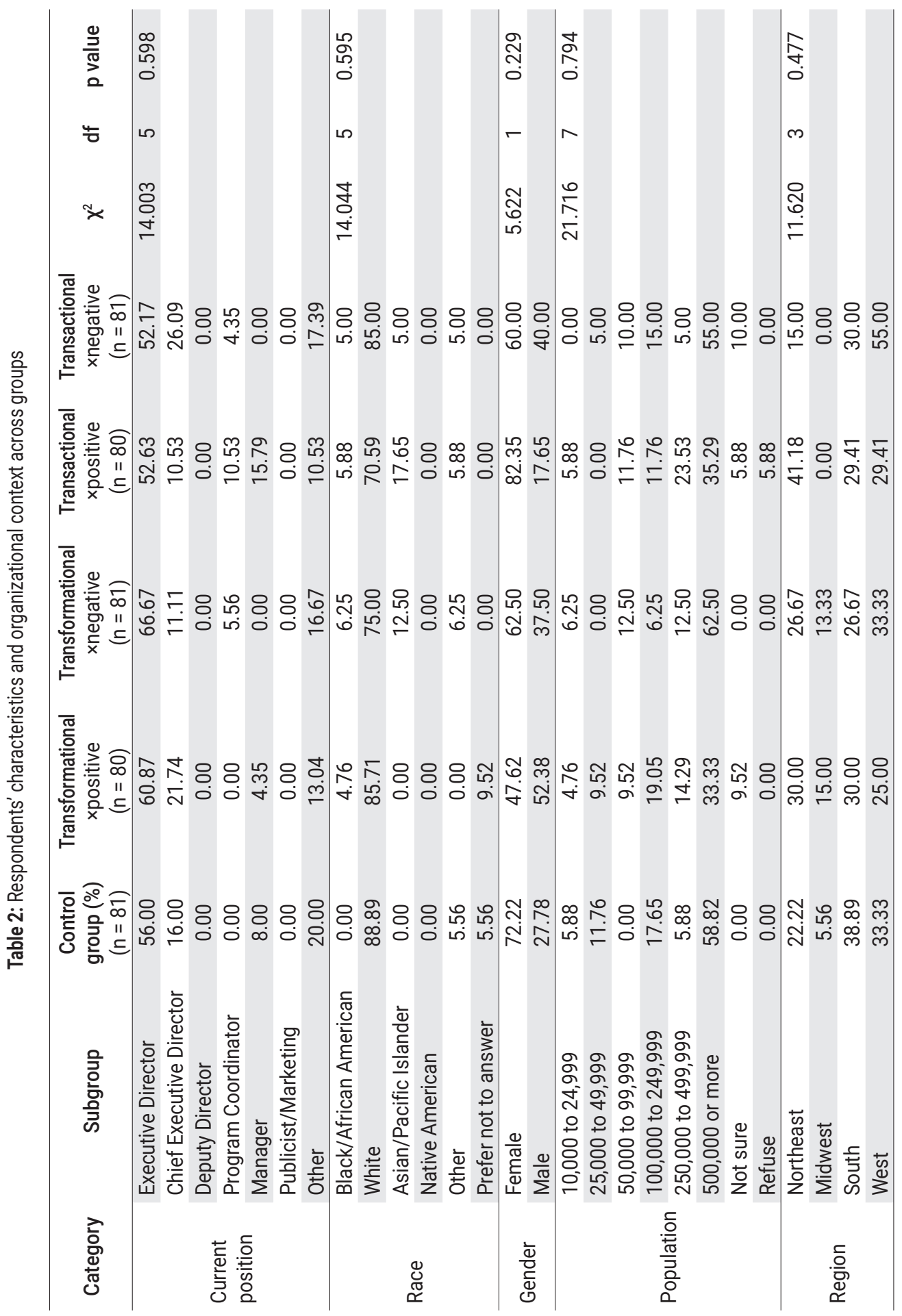


the positive behavior condition, participants were informed that a nonprofit leader has demonstrated his beliefs by showing actions consistent with his beliefs (see Appendix A).

To test the hypothesis of the positive-negative asymmetry effects, the positive behavior vignettes include the components of the relational authenticity as a leader. In the vignettes, relational authenticity is operationalized based on two components of authenticity defined by Avolio et al. (2004). With respect to the first component, authentic leaders support ideals that benefit the greater society and communicate these ideas to followers in a transparent manner. With respect to the second component, followers identify with public values and accept them as acceptable for the community in which they are affiliated - whether that community is a nation, an organization, or a group. To achieve relational authenticity, followers must provide leaders the authority to promote a set of public values on behalf of a community. Once assigned randomly to the positive behavior condition, respondents read an introductory statement about relational authenticity as a leader, that is phrased as follows:

'Since Bill Jacoby has worked in the nonprofit sector, he has demonstrated his beliefs by showing actions consistent with his beliefs. In other words, he makes personal decisions based on his core beliefs. For example, Bill Jacoby makes a monthly donation to Children's Cancer Association, and works as a voluntary teacher at the orphanages. Whenever he sees senior citizens or citizens with disabilities with limited mobility, he always offers his help to them. Through this personal experience, he has come to learn that he was most inspired when he donates, volunteers, or helps other people. He believes that the experience is indeed meaningful, as it helps him to reflect on life from a broader perspective - helping other people brought a balance to his life, which otherwise would have been filled only with work.'

\subsection{Measures}

The dependent variable, organizational performance, is a socially constructed phenomenon that is subjective, complex, and particularly difficult to measure, especially in the nonprofit sector (Au, 1996; Anspach, 1991). This study measures organizational performance following a perceptual measure grounded in a theoretical taxonomy proposed by Brewer and Selden (2000) and Kim (2005). This taxonomy differentiates between an organization's internal and external performance. Moreover, it specifies the following performance-related values: efficiency, effectiveness, and fairness. Meanwhile, we conducted factor analyses of six items from the 1996 Merit System Protection Board's Merit Principles Survey ${ }^{3}$. The index's Cronbach's $\alpha$ is .90. For the self-reported performance measures,

3 The item order of organizational performance was randomized to minimize response order biases. The survey questions used to measure organizational performance were ordered randomly to reduce response order effects using the item randomization option of Qualtrics. This is because of the possible priming effects (Van de Walle and Van Ryzin, 2011) in the preliminary phase of this research. 
this study endeavors to measure perceptions of organizational performance consistently with previous literature (Brewer and Selden, 2000; Kim, 2005). Our study's respondents are executive directors in real-world nonprofit organizations who evaluated hypothetical nonprofits' organizational performance, and did not assess their own organizational performance. The items are listed in Appendix B.

The transformational and transactional leadership items were adapted from the previous literature (Jensen et al., 2019; Antonakis et al., 2003). For the moderating variable, this study takes advantage of Walumbwa et al.'s (2008) eight-item survey of relational authenticity. The items' factor loadings and Cronbach alpha values are listed in Appendix C.

\section{Results}

Figure 3 shows a plot of the coefficients from regression analyses. The result provides evidence supporting Hypothesis 1. In this figure, the dots are regression coefficients on a set of dummy variables that contrast each treatment group with the control group, which is the horizontal line (reference group), with 95-percent confidence intervals (CIs) to show statistically significant differences. In Figure 3, the difference between transformational and transactional leadership effects was statistically significant at $p<0.05$ in the sample combining negative and positive personal behavior. For Table 3 , the coefficient for transformational leadership is positive, meaning that respondents assigned to transformational leadership ( $\mathrm{X}=1$ when observations are under transformational leadership treatments) expected this nonprofit to show higher organizational performance than those assigned to transactional leadership and control groups $(X=0)$. This relationship is statistically significant at $\mathrm{p}<0.01$. When the interaction terms were added to the model, the relationship remained statistically significant at $\mathrm{p}<0.05$. For the main effects of transformational leadership on organizational performance, nonprofit executive directors perceived that organizations with transformational leaders perform better than those with transactional leaders.

Regarding Hypothesis 2, the findings show that in the case of positive personal behavior, a transformational leader (vs. transactional leader) acting favorably has a positive influence on organizational performance. In the case of negative personal behavior, leadership styles have no significant effect on organizational performance. Looking at Figure 3, it can be seen that there is a statistically significant difference between transactional leadership $\times$ positive behaviors and transformational leadership $\times$ positive behavior at $\mathrm{p}<0.05$, whereas the two confidence intervals (transactional leadership $\times$ negative behaviors and transformational leadership $\times$ negative behaviors) overlapped. This outcome is evident from the interaction between transformational leadership and leaders' positive behavior (transformational leadership $=1$ ), which is positive and statistically significant at $\mathrm{p}<0.01$ (Table 3). Specifically, relational authenticity increased transformational leadership's positive effects on perceptions of organizational performance, as this positive relationship became stronger when leaders behaved positively. Thus, relational authenticity can improve the relationship between transformational leadership and perceptions of organizational performance, which is consistent with Hypothesis 2. 

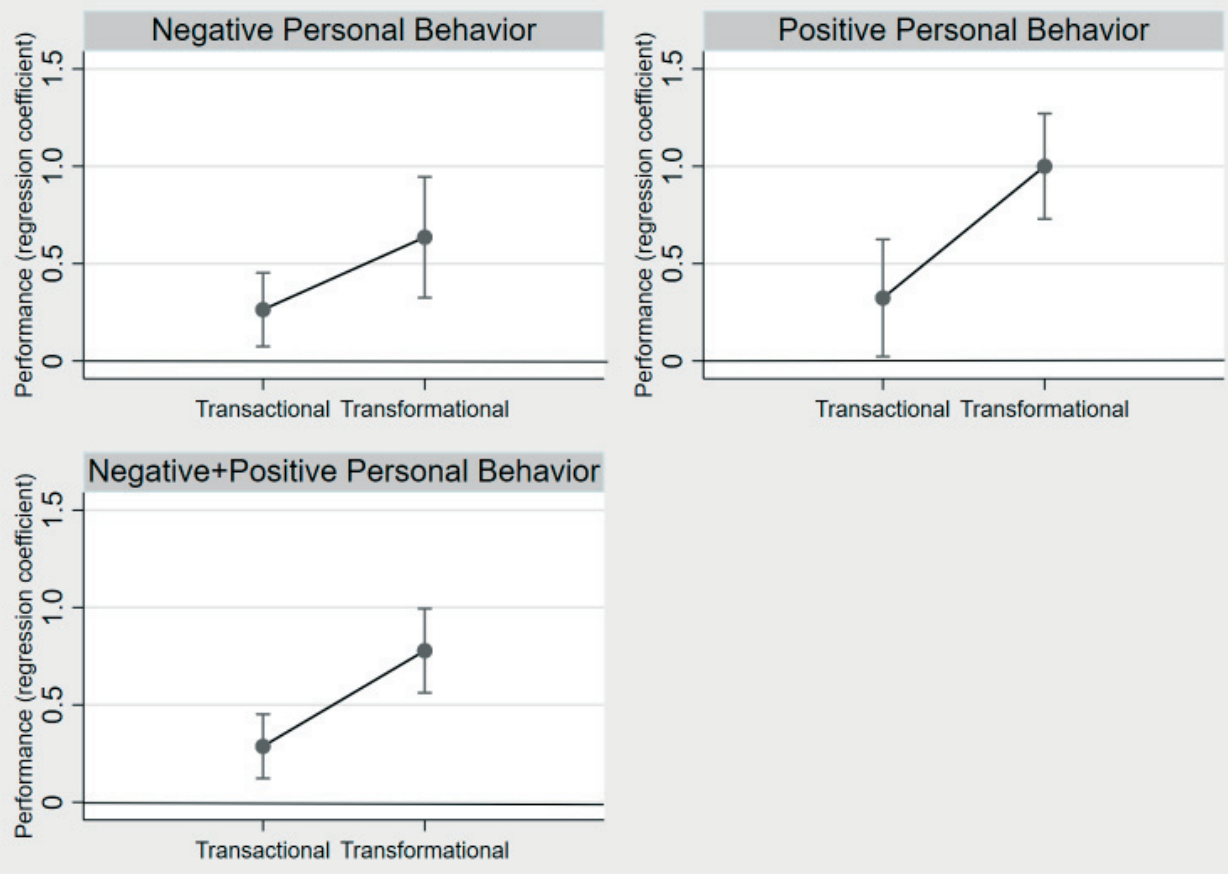

Note: Figure shows unstandardized regression coefficients, with 95-percent confidence intervals (Cls), from an OLS regression model in which each vignetted-condition is a separate dummy variable and the control condition is the reference group (horizontal line). The dependent variable is perceptions of organizational performance on a 1-5 rating scale. Cls that do not cross the horizontal line are statistically different from the reference group (at $p<.05)$. See Table 3 for the complete regression results.

Figure 3: Coefficient plot showing effects of leader's personal behavior on perceptions of organizational performance, relative to the control group

Source: Author

Table 3: Experimental results

\begin{tabular}{lcc}
\hline & DV=Organizational & Performance \\
\hline Ref: Control Group & Model 1 & Model 2 \\
Transformational Leadership (TFL) & $0.771^{\star \star \star}$ & $0.556^{\star \star}$ \\
(TFL=1) & $(0.189)$ & $(0.283)$ \\
TFL $\times$ Positive Personal Behavior & & $0.731^{\star \star \star}$ \\
& & $(0.212)$ \\
Positive Personal Behavior & $0.306^{\star \star \star}$ & $0.738^{\star}$ \\
(Positive=1) & $(0.409)$ & $(0.311)$ \\
TFL $\times$ Negative Personal Behavior & & $-0.339 \star \star$ \\
& & $(0.292)$ \\
Transactional Leadership (TAL) & $0.395^{\star \star}$ & $0.350^{\star \star}$ \\
(TAL=1) & $(0.569)$ & $(0.242)$ \\
TAL $\times$ Positive Personal Behavior & & 0.267 \\
& & $(0.292)$ \\
\hline
\end{tabular}




\begin{tabular}{lcc}
\hline & DV=Organizational & Performance \\
\hline Negative Personal Behavior & $-0.233^{\star \star \star}$ & $-0.101^{\star \star}$ \\
$($ Negative $=1)$ & $(0.423)$ & $(0.283)$ \\
TAL $\times$ Negative Personal Behavior & & $-0.395^{\star}$ \\
& & $(0.569)$ \\
Constant & $2.260^{\star \star \star}$ & $2.700^{\star \star \star}$ \\
N & $(0.168)$ & $(0.281)$ \\
Adjusted R2 & 403 & 403 \\
\hline
\end{tabular}

Note: Table shows unstandardized OLS regression coefficients. Standard errors in parentheses. DV means dependent variable. Ref stands for reference group.

${ }^{*} p<0.10 ;{ }^{* *} p<0.05 ; * \star * p<0.01$ (two-tailed tests)

Source: Author

\section{Discussion and conclusion}

This study sought to contribute to the literature on leadership style by examining whether the effect of transformational and transactional leadership on nonprofit executives' perceptions of organizational performance varies depending on relational authenticity as a leader. The results show that achieving relational authenticity moderates the effect of leadership style, which is a direct determinant of perceptions of organizational performance. If leaders possess relational authenticity, they will have greater self-awareness and self-regulated positive behavior on the part of their supervisors and the followers, which in turn will have favorable effects on organizational performance (Avolio and Gardner, 2005).

Concerning Hypothesis 1 , the result shows that transformational leadership has a positive effect on organizational performance compared to transactional leadership. These findings reiterate conclusions drawn from previous research - that is, transformational leadership is a key determinant of perceptions of organizational performance (Bellé, 2014; Paarlberg and Lavigna, 2010). Further, this study expands our current knowledge by explicating the moderating effect of relational authenticity on the leadership - performance association.

Consistent with the positive-negative asymmetry effect hypothesis (Hypothesis 2), this study supports the assumption that, in the case of positive personal behavior, a transformational leader (vs. transactional leader) acting favorably has a statistically significant and positive influence on organizational performance. By contrast, in the case of negative personal behavior, the treatment had null findings. When leaders behave positively, the gap between transformational and transactional leadership effects is greater than when leaders act negatively. Leaders' negative behavior counters both leadership effects, perhaps because adverse impressions and inhospitable stereotypes form more quickly and are more resistant to change than the good ones.

The results of this study have important implications for future research. In terms of practice, our study suggests that nonprofit managers and executives can use relational au- 
thenticity to improve their strategic and managerial practices that benefit performance. Multiple factors contribute to perceptions of organizational performance, and this study shows that leaders' inappropriate behavior may have adverse effects on perceptions of organizational performance. More fundamentally, nonprofit executive directors must be careful about their personal conduct at all times because inappropriate conduct has a detrimental effect on organizational performance regardless of leadership style.

Moreover, many forms of achieving relational authenticity (e.g., being polite to police officers when pulled over because of traffic violations, and treating citizens with dignity and respect) are not economically costly. The virtues of leaders' positive personal behavior have been praised; therefore, this study suggests that leaders who provide leadership training should consider focusing on achieving relational authenticity to ensure the sustainability of transformational leadership in nonprofit organizations.

Finally, the study's findings need to be interpreted with caution for several reasons. First, the results are based on a simulated setting that may not be generalizable to real-world leadership behavior. Interestingly, future studies might perform an experiment in which participants assess real organizations' leadership style and evaluate the moderation effect of relational authenticity on organizational performance to provide more realism in their task. Second, this study measured managers' perceptions of organizational performance, although past studies have used financial performance measures. Several previous studies have suggested other measures of organizational performance. For example, O'Sullivan et al. (2016) identified administrative records, customer feedback, rating systems, census data, and government records as data sources that nonprofit administrators can use to measure organizational performance. Future research using these alternative organizational performance measures, such as that used by O'Sullivan et al. (2016), is needed to explore the extent to which these findings are robust.

Notwithstanding these limitations, the findings offer several practical implications. First, and perhaps most importantly, relational authenticity as a leader, more than transformational leadership itself, appears to form the basis for improving the performance of their organizations. Nonprofit leaders must consider the larger impact of their personal behaviors, as well as the community in which they work. These considerations raise employee awareness, model sincerely held beliefs, and promote accountability for one's actions. By doing so, leaders must show that they understand the human/cultural dimension is the driving reason behind organizational performance. This is the kind of insight that leaders who want to make their organizational performance better need. Nonprofits seeking a return on investment from the cost of hiring the best talents must make such a shift.

Second, to put an organization on a path to success, today's transformational leaders must balance talent development and social justice with the organization's overall aims. Nonprofit executives and managers have the power to shape not only what happens in their workplace, but also how they process those moments. In turn, followers will be naturally inclined to perform even more for the organization than the basic requirements. This participatory approach will minimize the unintended consequences of innovation while sustaining progress in the workplace. 
Lastly, leaders must understand the importance of their relational authenticity as a leader. A manager is much more effective as a transformative manager because the manager has the respect of his/her followers and sets a positive example for them daily. Further, the followers are more likely to work harder for the organizations because he/she has such a positive effect on his/her employees. Whereas the negative manager is usually feared by the staff and will only do what they are required to do, nothing extra. The negative manager is usually disliked by the staff due to their personal behaviors outside their workplace. On the other hand, the positive manager is generally universally well-liked and staff will work more effectively because they know management appreciates them. However, the negative manager is not liked by many people and doesn't appreciate the staff or their productivity. As such, followers are very unlikely to work longer or to put a concerted effort for any reason other than overtime pay.

All in all, this study's findings explicate the importance of relational authenticity when evaluating the effects of leadership style on perceptions of organizational performance. Although transformational or transactional leadership is often proposed to improve or decrease organizational performance, we note the importance of delineating relational authenticity that shapes how leadership style impacts organizational performance. Indeed, focusing on leadership style, such as transformational and transactional leadership, alone will likely paint an incomplete picture of the mechanisms responsible for translating leadership style into organizational performance. Rather, to build a completer and more nuanced picture, our findings offer preliminary evidence on the importance of achieving relational authenticity as a leader.

\section{References:}

1. Anspach, R.R., 'Everyday Methods for Assessing Organizational Effectiveness', 1991, Social Problems, vol. 38, no. 1, pp. 1-19.

2. Antonakis, J., Avolio, B.J. and Sivasubramaniam, N., 'Context and Leadership: An Examination of the Nine-factor Full-range Leadership Theory Using the Multifactor Leadership Questionnaire', 2003, The Leadership Quarterly, vol. 14, no. 3, pp. 261-295.

3. Au, C.-f., 'Rethinking Organizational Effectiveness: Theoretical and Methodological Issues in the Study of Organizational Effectiveness for Social Welfare Organizations', 1996, Administration in Social Work, vol. 20, no. 4, pp. 1-21.

4. Avolio, B.J. and Gardner, W.L., 'Authentic Leadership Development: Getting to the Root of Positive Forms of Leadership', 2005, The Leadership Quarterly, vol. 16, no. 3, pp. 315-338.

5. Avolio, B.J., Gardner, W.L., Walumbwa, F.O., Luthans, F. and May, D.R., 'Unlocking the Mask: A Look at the Process by Which Authentic Leaders Impact Follower Attitudes and Behaviors', 2004, The Leadership Quarterly, vol. 15, no. 6, pp. 801-823.

6. Barling, J., Weber, T. and Kelloway, E.K., 'Effects of Transformational Leadership Training on Attitudinal and Financial Outcomes: A Field Experiment', 1996, Journal of Applied Psychology, vol. 81 , no. 6, pp. 827-832.

7. Bass, B.M. and Avolio, B.J., Improving Organizational Effectiveness through Transformational Leadership, Thousand Oaks, CA: Sage Publications, 1994. 
8. Bass, B.M. and Avolio, B.J., MLQ: Multifactor Leadership Questionnaire, Redwood City, CA: Mind Garden, 2000.

9. Baumeister, R.F., Bratslavsky, E., Finkenauer, C. and Vohs, K.D., 'Bad Is Stronger than Good', 2001, Review of General Psychology, vol. 5, no. 4, pp. 323-370.

10. Bellé, N., 'Leading to Make a Difference: A Field Experiment on the Performance Effects of Transformational Leadership, Perceived Social Impact, and Public Service Motivation', 2014, Journal of Public Administration Research and Theory, vol. 24, no. 1, pp. 109-136.

11. Boerner, S. and Gebert, D., 'Fostering Artistic Ensemble Performance: Exploring the Role of Transformational Leadership', 2012, Nonprofit Management and Leadership, vol. 22, no. 3, pp. 347-365.

12. Brewer, G.A. and Selden, S.C., 'Why Elephants Gallop: Assessing and Predicting Organizational Performance in Federal Agencies', 2000, Journal of Public Administration Research and Theory, vol. 10, no. 4, pp. 685-711.

13. Brimhall, K.C., 'Inclusion and Commitment as Key Pathways between Leadership and Nonprofit Performance', 2019, Nonprofit Management and Leadership, vol. 30, no. 1, pp. 31-49.

14. Chen, Y., Ning, R., Yang, T., Feng, S. and Yang, C., 'Is Transformational Leadership Always Good for Employee Task Performance? Examining Curvilinear and Moderated Relationships', 2018, Frontiers of Business Research in China, vol. 12, no. 1, pp. 1-28.

15. Creative Business Resources, '5 Key HR Issues Facing Nonprofit Organizations', 2016, [Online] available at https://cbri.com/5-key-hr-issues-facing-nonprofit-organizations/, accessed on August 24, 2021.

16. De Vita, C.J. and Fleming, C.(eds.), Building Capacity in Nonprofit Organizations, Washington, DC: Urban Institute, 2001.

17. Dillman, D.A., Smyth, J.D. and Christian, L.M., Internet, Phone, Mail, and Mixed-mode Surveys: The Tailored Design Method, Hoboken, NJ: John Wiley \& Sons, 2014.

18. Dvir, T., Eden, D., Avolio, B.J. and Shamir, B., 'Impact of Transformational Leadership on Follower Development and Performance: A Field Experiment', 2002, Academy of Management Journal, vol. 45, no. 4, pp. 735-744.

19. Eagly, A.H., 'Achieving Relational Authenticity in Leadership: Does Gender Matter?', 2005, The Leadership Quarterly, vol. 16, no. 3, pp. 459-474.

20. Faul, F., Erdfelder, E., Lang, A.G. and Buchner, A., 'G* Power 3: A Flexible Statistical Power Analysis Program for the Social, Behavioral, and Biomedical Sciences', 2007, Behavior Research Methods, vol. 39, no. 2, pp. 175-191.

21. García-Morales, V.J., Jiménez-Barrionuevo, M.M. and Gutiérrez-Gutiérrez, L., 'Transformational Leadership Influence on Organizational Performance through Organizational Learning and Innovation', 2012, Journal of Business Research, vol. 65, no. 7, pp. 1040-1050.

22. Geer, B.W., Maher, J.K. and Cole, M.T., 'Managing Nonprofit Organizations: The Importance of Transformational Leadership and Commitment to Operating Standards for Nonprofit Accountability', 2008, Public Performance \& Management Review, vol. 32, no. 1, pp. 51-75.

23. George, B., Sims, P., McLean, A.N. and Mayer, D., 'Discovering Your Authentic Leadership', 2007, Harvard Business Review, vol. 85, no. 2, pp. 129-137.

24. Harter, S., 'Authenticity', in Snyder, C.R. and Lopez, S. (eds.), Handbook of Positive Psychology, Oxford: Oxford University Press, 2002, pp. 382-294.

25. Horton, J.J., Rand, D.G. and Zeckhauser, R.J., 'The Online Laboratory: Conducting Experiments in a Real Labor Market', 2011, Experimental Economics, vol. 14, no. 3, pp. 399-425. 
26. Jaskyte, K., 'Transformational Leadership, Organizational Culture, and Innovativeness in Nonprofit Organizations', 2004, Nonprofit Management and Leadership, vol. 15, no. 2, pp. 153-168.

27. Jensen, U.T., Andersen, L.B., Bro, L.L., Bøllingtoft, A., Eriksen, T.L.M., Holten, A.L., Salomonsen, H.H., Westergard-Nielsen, N. and Wurtz, A., 'Conceptualizing and Measuring Transformational and Transactional Leadership', 2019, Administration \& Society, vol. 51, no. 1, pp. 3-33.

28. Jung, D.I. and Avolio, B.J., 'Opening the Black Box: An Experimental Investigation of the Mediating Effects of Trust and Value Congruence on Transformational and Transactional Leadership', 2000, Journal of Organizational Behavior, vol. 21, no. 8, pp. 949-964.

29. Kim, M. and Charbonneau, E., 'Caught between Volunteerism and Professionalism: Support by Nonprofit Leaders for the Donative Labor Hypothesis', 2020, Review of Public Personnel Administration, vol. 40, no. 2, pp. 327-349.

30. Kim, S., 'Individual-level Factors and Organizational Performance in Government Organizations', 2005, Journal of Public Administration Research and Theory, vol. 15, no. 2, pp. 245-261.

31. Kotzé, M. and Nel, P., 'Personal Factor Effects on Authentic Leadership', 2017, Journal of Psychology in Africa, vol. 27, no. 1, pp. 47-53.

32. Martijn, C., Spears, R., Van der Pligt, J. and Jakobs, E., 'Negativity and Positivity Effects in Person Perception and Inference: Ability versus Morality', 1992, European Journal of Social Psychology, vol. 22, no. 5, pp. 453-463.

33. Mason, W. and Suri, S., 'Conducting Behavioral Research on Amazon's Mechanical Turk', 2012, Behavior Research Methods, vol. 44, no. 1, pp. 1-23.

34. Mayr, M.L., 'Transformational Leadership and Volunteer Firefighter Engagement: The Mediating Role of Group Identification and Perceived Social Impact', 2017, Nonprofit Management and Leadership, vol. 28, no. 2, pp. 259-270.

35. Merit System Protection Board, Merit Principles Survey, U.S., 2016.

36. National Center for Charitable Statistics, National Center for Charitable Statistics NCCS, 2013, [Online] available at http://nccs.urban.org/, accessed on February 20, 2022.

37. Oppenheimer, D.M., Meyvis, T. and Davidenko, N., 'Instructional Manipulation Checks: Detecting Satisficing to Increase Statistical Power', 2009, Journal of Experimental Social Psychology, vol. 45, no. 4, pp. 867-872.

38. O’Sullivan, E., Rassel, G.R. and Taliaferro, J.D., Practical Research Methods for Nonprofit and Public Administrators, New York: Routledge, 2016.

39. Paarlberg, L.E. and Lavigna, B., 'Transformational Leadership and Public Service Motivation: Driving Individual and Organizational Performance', 2010, Public Administration Review, vol. 70, no. 5, pp. $710-718$.

40. Peeters, G. and Czapinski, J., 'Positive-negative Asymmetry in Evaluations: The Distinction between Affective and Informational Negativity Effects', 1990, European Review of Social Psychology, vol. 1, no. 1, pp. 33-60.

41. Reeder, G.D. and Brewer, M.B., 'A Schematic Model of Dispositional Attribution in Interpersonal Perception', 1979, Psychological Review, vol. 86, no. 1, pp. 61-79.

42. Reeder, G.D. and Coovert, M.D., 'Revising an Impression of Morality', 1986, Social Cognition, vol. 4, no. 1, pp. 1-17.

43. Riggio, R.E., Bass, B.M. and Orr, S.S., 'Transformational Leadership in Nonprofit Organizations', in Riggio, R.E. and Orr, S.S. (eds.), Improving Leadership in Nonprofit Organizations, San Francisco, CA: Jossey-Bass, 2004, pp. 49-62. 
44. Rowold, J., Borgmann, L. and Bormann, K., 'Which Leadership Constructs Are Important for Predicting Job Satisfaction, Affective Commitment, and Perceived Job Performance in Profit versus Nonprofit Organizations?', 2014, Nonprofit Management and Leadership, vol. 25, no. 2, pp. 147-164.

45. Rowold, J. and Rohmann, A., 'Transformational and Transactional Leadership Styles, Followers' Positive and Negative Emotions, and Performance in German Nonprofit Orchestras', 2009, Nonprofit Management and Leadership, vol. 20, no. 1, pp. 41-59.

46. Shamir, B. and Eilam, G., 'What's Your Story?' A Life-stories Approach to Authentic Leadership Development', 2005, The Leadership Quarterly, vol. 16, no. 3, pp. 395-417.

47. Skowronski, J.J. and Carlston, D.E., 'Social Judgment and Social Memory: The Role of Cue Diagnosticity in Negativity, Positivity, and Extremity Biases', 1987, Journal of Personality and Social Psychology, vol. 52, no. 4, pp. 689-699.

48. Skowronski, J.J. and Carlston, D.E., 'Negativity and Extremity Biases in Impression Formation: A Review of Explanations', 1989, Psychological Bulletin, vol. 105, no. 1, pp. 131-142.

49. Skowronski, J.J. and Carlston, D.E., 'Caught in the Act: When Impressions Based on Highly Diagnostic Behaviours Are Resistant to Contradiction', 1992, European Journal of Social Psychology, vol. 22, no. 5, pp. 435-452.

50. Third Sector Company, 'Nonprofit Leadership Development: The Importance of Leadership in Nonprofit Organizations', 2020, [Online] available at https://thirdsectorcompany.com/im portance-leadership-nonprofit-organizations/, accessed on August 24, 2021.

51. University of Notre Dame, 'How Transformational Leadership Guides Nonprofits. Nonprofit Leadership', 2019, [Online] available at https://www.notredameonline.com/resources/non profit-leadership/how-transformational-leadership-guides-nonprofits/, accessed on August 24, 2021.

52. Van de Walle, S. and Van Ryzin, G.G., 'The Order of Questions in a Survey on Citizen Satisfaction with Public Services: Lessons from a Split-ballot Experiment', 2011, Public Administration, vol. 89, no. 4, pp. 1436-1450.

53. Van Knippenberg, D. and Sitkin, S.B., 'A Critical Assessment of Charismatic - Transformational Leadership Research: Back To the Drawing Board?', 2013, The Academy of Management Annals, vol. 7, no. 1, pp. 1-60.

54. Van Slyke, D.M. and Johnson, J.L., 'Nonprofit Organizational Performance and Resource Development Strategies', 2006, Public Performance \& Management Review, vol. 29, no. 4, pp. 467-496.

55. Walumbwa, F.O., Avolio, B.J., Gardner, W.L., Wernsing, T.S. and Peterson, S.J., 'Authentic Leadership: Development and Validation of a Theory-based Measure', 2008, Journal of Management, vol. 34, no. 1, pp. 89-126.

56. Wang, G., Oh, I.S., Courtright, S.H. and Colbert, A.E., 'Tranformational Leadership and Performance across Criteria and Levels: A Meta-Analytic Review of 25 Years of Research', 2011, Group \& Organization Management, vol. 36, no. 2, pp. 223-270.

57. Whittington, J.L., Goodwin, V.L. and Murray, B., 'Transformational Leadership, Goal Difficulty, and Job Design: Independent and Interactive Effects on Employee Outcomes', 2004, The Leadership Quarterly, vol. 15, no. 5, pp. 593-606. 


\section{Appendix A.}

\section{Experimental Vignettes}

The next questions are based on a hypothetical scenario of leadership effects on organizational performance. Please respond to the questions based on Bill Jacoby's leadership style, and its effects on organizational performance. Please assume that you are Bill Jacoby's boss.

\section{(1) Transformational leadership and negative personal behavior}

Bill Jacoby is a leader who addresses subordinates' motivation, and is very much focused on his relationship with them. He inspires and motivates followers by appealing to higher ideas and moral values. He encourages his followers to transcend their own interests for the sake of the organization.

Bill Jacoby presently is a deputy director of a 501(c)(3) organization called Confidence, a diverse, urban, and multi-service nonprofit in Blanchard City, where he manages the operations and oversees the programmatic implementation of services. He has raised over $\$ 7$ million in new funding since October 2000. He hired, trained, and supervised over 40 staff members and volunteers.

Before joining Confidence, Jacoby worked in San Juan, Puerto Rico in a community development initiative for public housing projects. He also was the executive director of a multi-service nonprofit organization called St. Columba Club, Inc. in Blanchard City. Jacoby has served on a number of nonprofit boards and advisory councils.

Bill Jacoby, the deputy director of Confidence, told the Blanchard University Police Department he was not his 'best self' on the March morning when campus police tried to investigate a minor accident between his driver and a campus police car.

An officer's body camera video shows a very awkward moment involving Jacoby and the campus police. Jacoby apologized after body cam footage showed him shouting out at the police who held him at the scene of a fender bender briefly. In the video, Jacoby also made sure to mention that he was the deputy director.

'If I miss my airplane, you folks are in trouble', Jacoby said as he pointed his finger angrily at an officer at the scene, according to the footage Kansas Advance Media obtained.

According to KS.com, this incident stemmed from a minor car accident. Jacoby told the police he was on his way to the airport when his driver's vehicle was in a minor accident involving a police vehicle.

Officers detained Jacoby and his driver at the scene while they assessed any damage that might have resulted. As seen in the footage, one of the police officers arrived at the scene, and asked who he was.

'I'm the deputy director', he yelled. 'I'd love to see them do this to President Rory', he added, referring to Blanchard University's president.

According to Blanchard University officials, a driver in a black sedan had arrived to pick Jacoby up at the Center for Law and Justice on South Blount Street in Blanchard City to take him to the airport. According to Kansas Advance Media, the sedan hit the bumper of a campus police car that was parked along the curb, which caused the car to 
jolt. The officer in the police car began to investigate the fender bender and acquire details for a report.

\section{(2) Transformational leadership and positive personal behavior}

Bill Jacoby is a leader who addresses subordinate motivation, and is very much focused on his relationship with them. He inspires and motivates followers by appealing to higher ideas and moral values. Jacoby encourages his followers to transcend their own interests for the sake of the organization.

Jacoby presently is a deputy director of a 501(c)(3) organization called Confidence, a diverse, urban, and multi-service nonprofit in Blanchard City, where he manages the operations and oversees the programmatic implementation of services. He has raised over $\$ 7$ million in new funding since October 2000. He hired, trained, and supervised over 40 staff members and volunteers.

Before joining Confidence, Jacoby worked in San Juan, Puerto Rico in a community development initiative for public housing projects. He also was the executive director of a multi-service nonprofit organization called St. Columba Club, Inc. in Blanchard City. Jacoby has served on a number of nonprofit boards and advisory councils.

Since Bill Jacoby has worked in the nonprofit sector, he has demonstrated his beliefs by showing actions consistent with his beliefs. In other words, he makes personal decisions based on his core beliefs. For example, Bill Jacoby makes a monthly donation to Children's Cancer Association, and works as a voluntary teacher at the orphanages. Whenever he sees senior citizens or citizens with disabilities with limited mobility, he always offers his help to them. Through this personal experience, he has come to learn that he was most inspired when he donates, volunteers, or helps other people. He believes that the experience is indeed meaningful, as it helps him to reflect on life from a broader perspective - helping other people brought a balance to his life, which otherwise would have been filled only with work.

\section{(3) Transactional leadership and negative personal behavior}

Bill Jacoby is a leader who promotes followers' compliance through both rewards and discipline. Through this system, he motivates his followers by appealing to their self-interests. Jacoby keeps his relationship with his followers in terms of exchange for the short-term.

Jacoby presently is a deputy director of a 501(c)(3) organization called Confidence, a diverse, urban, and multi-service nonprofit in Blanchard City, where he manages the operations and oversees the programmatic implementation of services. He has raised over $\$ 7$ million in new funding since October 2000. He hired, trained, and supervised over 40 staff members and volunteers.

Before joining Confidence, Jacoby worked in San Juan, Puerto Rico in a community development initiative for public housing projects. He also was the executive director of a multi-service nonprofit organization called St. Columba Club, Inc. in Blanchard City. Jacoby has served on a number of nonprofit boards and advisory councils.

Jacoby told the Blanchard University Police Department he was not his 'best self' on the March morning when campus police tried to investigate a minor accident between his driver and a campus police car. 
An officer's body camera video shows a very awkward moment involving Jacoby and the campus police. Jacoby apologized after body cam footage showed him shouting out at the police who held him at the scene of a fender bender briefly. In the video, Jacoby also made sure to mention that he was the deputy director.

'If I miss my airplane, you folks are in trouble', Jacoby said as he pointed his finger angrily at an officer at the scene, according to the footage Kansas Advance Media obtained.

According to KS.com, this incident stemmed from a minor car accident. Jacoby told the police he was on his way to the airport when his driver's vehicle was in a minor accident involving a police vehicle.

Officers detained Jacoby and his driver at the scene while they assessed any damage that might have resulted. As seen in the footage, one of the police officers arrived at the scene, and asked who he was.

'I'm the deputy director', he yelled. 'I'd love to see them do this to President Rory', he added, referring to Blanchard University's president.

According to Blanchard University officials, a driver in a black sedan had arrived to pick Jacoby up at the Center for Law and Justice on South Blount Street in Blanchard City to take him to the airport. According to Kansas Advance Media, the sedan hit the bumper of a campus police car that was parked along the curb, which caused the car to jolt. The officer in the police car began to investigate the fender bender and acquire details for a report.

\section{(4) Transactional leadership and positive personal behavior}

Bill Jacoby is a leader who promotes followers' compliance through both rewards and discipline. Through this system, he motivates his followers by appealing to their self-interests. Jacoby keeps his relationship with his followers in terms of exchange for the shortterm.

Jacoby presently is a deputy director of a 501(c)(3) organization called Confidence, a diverse, urban, and multi-service nonprofit in Blanchard City, where he manages the operations and oversees the programmatic implementation of services. He has raised over $\$ 7$ million in new funding since October 2000. He hired, trained, and supervised over 40 staff members and volunteers.

Before joining Confidence, Jacoby worked in San Juan, Puerto Rico in a community development initiative for public housing projects. He also was the executive director of a multi-service nonprofit organization called St. Columba Club, Inc. in Blanchard City. Jacoby has served on a number of nonprofit boards and advisory councils.

Since Bill Jacoby has worked in the nonprofit sector, he has demonstrated his beliefs by showing actions consistent with his beliefs. In other words, he makes personal decisions based on his core beliefs. For example, Bill Jacoby makes a monthly donation to Children's Cancer Association, and works as a voluntary teacher at the orphanages. Whenever he sees senior citizens or citizens with disabilities with limited mobility, he always offers his help to them. Through this personal experience, he has come to learn that he was most inspired when he donates, volunteers, or helps other people. He believes that the experience is indeed meaningful, as it helps him to reflect on life from a broader perspective - helping 
other people brought a balance to his life, which otherwise would have been filled only with work.

\section{(5) Control group}

Bill Jacoby presently is a deputy director of a 501(c)(3) organization called Confidence, a diverse, urban, and multi-service nonprofit in Blanchard City, where he manages the operations and oversees the programmatic implementation of services. He has raised over $\$ 7$ million in new funding since October 2000. He hired, trained, and supervised over 40 staff members and volunteers.

Before joining Confidence, Jacoby worked in San Juan, Puerto Rico in a community development initiative for public housing projects. He also was the executive director of a multi-service nonprofit organization called St. Columba Club, Inc. in Blanchard City. Jacoby has served on a number of nonprofit boards and advisory councils.

\section{Appendix B.}

\section{Measures of organizational performance}

After reading the hypothetical scenario for each group, respondents were then asked: 'The following questions refer to a hypothetical scenario. To what extent, if at all, do you agree with the following statements as they relate to the performance of the organization with which he is involved? (Select one answer in each row.)

- His organization has made good use of the coworkers' knowledge and skills to become more efficient.

- In the past two years, his work unit's productivity has improved.

- His work unit's performance provides the public a worthwhile return on their donation dollars.

- In general, everyone in his organization is treated with respect, without regard to status and grade.

- Overall, the quality of work his current coworkers in his immediate work group perform is high.

- His organization treats employees and applicants fairly and equitably in all aspects of personnel management without regard to their political affiliation, sex, hometown, marital status, age, or disability condition.'

Respondents answered on a 1-5 scale, where 1 indicated 'Strongly disagree', 2 - 'Somewhat disagree', 3 - 'Neither agree nor disagree', 4 - 'Somewhat agree', and 5 - 'Strongly agree'. 
Appendix C.

Measures of transformational, transactional, and authentic leadership

When it concerns [Bill Jacoby's leadership style]

Response Options: 1 = strongly disagree, 5 = strongly agree

PCF (varimax) factor loadings and Cronbach alphas

Transformational Leadership (alpha $=.82$ )

'Concretizes a clear vision for the [ORGANIZATION'S] future' 0.79

'Seeks to make employees accept common goals for the [ORGANIZATION]' 0.80

'Strives to get the [ORGANIZATION'S] employees to work together in the direction of the vision' 0.86

'Strives to clarify for the employees how they can contribute to achieving the [ORGANIZATION'S] goals' 0.79

Transactional Leadership (alpha $=.91$ )

Transactional Leadership: Verbal Rewards

'Gives individual employees positive feedback when they perform well' 0.88

'Actively shows his/her appreciation of employees who do their jobs better than expected' 0.89

'Personally compliments employees when they do outstanding work' 0.91

Transactional Leadership: Pecuniary Rewards

'Rewards the employees' performance when they live up to his/her requirements' 0.85

'Rewards the employees dependent on how well they perform their jobs' 0.81

'Points out what employees will receive if they do what is required' 0.66

Transactional Leadership: Use of Contingent Sanctions

'Gives negative consequences to the employees if they perform worse than their colleagues' 0.87

'Makes sure that it has consequences for the employees if they do not consistently perform as required' 0.87 'Gives negative consequences to the employees if they do not perform as he/she requires' 0.87

Authentic Leadership (alpha $=.85$ )

Authentic Leadership: Self-Awareness

'Seeks feedback to improve interactions with others' 0.85

'Accurately describes how others view his or her capabilities' 0.93

Authentic Leadership: Relational Transparency

'Says exactly what he or she means' 0.82

'Is willing to admit mistakes when they are made' 0.79

Authentic Leadership: Internalized Moral Perspective

'Demonstrates beliefs that are consistent with actions' 0.82

'Makes decisions based on his/her core beliefs' 0.66

Authentic Leadership: Balanced Processing

'Solicits views that challenge his or her deeply held positions' 0.74

'Listens carefully to different points of view before coming to conclusions' 0.87

Note: For all dimensions of transformational, transactional leadership, and relational authenticity across the different vignettes, confirmatory factor analyses were conducted based on asymptotic distribution free estimator. All standardized factor loadings are statistically significant at $p<0.001$. 